\title{
If You Give a Kid an Oyster: Reflections on Collaborations in Place- Based STEM Education Through Oyster Restoration Science in New York City
}

\author{
Elisa Caref', Melissa Rex², Annie Lederberg'3 ${ }^{3}$ and Gaylen Moore ${ }^{4}$
}

${ }^{1}$ Sarah Lawrence College, Center for the Urban River at Beczak, Yonkers, NY; ${ }^{2}$ The River Project, New York, NY; ${ }^{3}$ Billion Oyster Project, New York, NY; ${ }^{4}$ Gaylen Moore Program Evaluation Services, New York, NY

DOI:10.15695/jstem/v1i1.13

Keywords: Ecology, Restoration, New York Harbor, Oysters, Professional Development, STEM, Field Science

\begin{abstract}
Many urban New Yorkers believe that the Hudson River is so polluted that nothing could possibly live there. In reality, the estuary is thriving, and The River Project (TRP), a marine science field station in lower Manhattan, exists to showcase its vast biodiversity through place-based education. In 2014, TRP began collaborating on a city-wide initiative with the Billion Oyster Project and nine other partner organizations to integrate restoration science into Title I middle school curricula through the Curriculum and Community Enterprise for Restoration Science (CCERS). Teachers in the fellowship program attend science workshops and professional development opportunities to bring the locally relevant topic of oyster restoration into their classrooms. Through this partnership, TRP has expanded its reach beyond the typical 90-minute field trip experience, fostering relationships with teachers through professional development workshops and in-classroom lessons to support their students' project-based learning explorations. This confluence of educational activities created a richer, more meaningful learning experience for teachers, students, and TRP educators.
\end{abstract}

\section{INTRODUCTION}

Dispelling the Dead River Myth. It is a widely held belief among residents of New York City that the Hudson River is a "dead river," spoiled by hundreds of years of urban pollution. Perhaps for this reason, waterways surrounding the island city are historically underutilized for educational purposes. In reality, the Hudson River and New York Harbor are experiencing an ecological revival, with a multitude of native species returning to and proliferating in its waters (Stanne, 2015). Species such as the striped bass, lined seahorse, and blue crab abound in the Hudson River Estuary, much to the surprise and delight of New Yorkers unfamiliar with the thriving ecosystem in their aquatic backyard.

Murky, green waters do little to dispel negative perceptions of the Hudson that linger from the days when the river was a repository for everything from chemical to human waste. Although the color, caused by billions of tiny photosynthetic plankton, represents a productive ecosystem (Stanne, 2007), many people associate the green color with toxicity. The cloudiness of the water, a combination of suspended plankton and silt, obscures views of the charismatic fauna beneath the Hudson's surface.

It was the predicament of the Hudson's inaccessibility that gave rise to The River Project 32 years ago. At its inception, The River Project (TRP) operated the only flowthrough aquarium in New York City, pumping unfiltered water from the Hudson River Estuary to nourish a variety of native species housed in its tanks. Today, the marine science field station, located on a pier in Lower Manhattan, still remains somewhat of an anomaly. While many environmental education programs have been established in the years since its founding, few allow students and the public the same level of intimate interaction with the Hudson River and its inhabitants as TRP's Wetlab, a 4,000-gallon flow-through aquarium system.

Connecting New Yorkers to Their River. The Wetlab, originally conceived as a hub of estuarine science research, quickly expanded into an educational center to fill a void in place-based environmental education in New York City. Since 1995, The River Project has hosted field trips for over 
20,000 students. During field trips, students from pre-kindergarten through college are introduced to urban ecology, field science, and the river's often-elusive inhabitants (Figure 1). Classes learn science through fieldwork, such as measuring water quality and checking traps, which highlight relationships between the abiotic and biotic elements of the ecosystem. All field trips are designed to align with grade level, as well as state and federal science standards. Teachers are offered a variety of topics and skills that can be covered during the trips, to better complement class work.

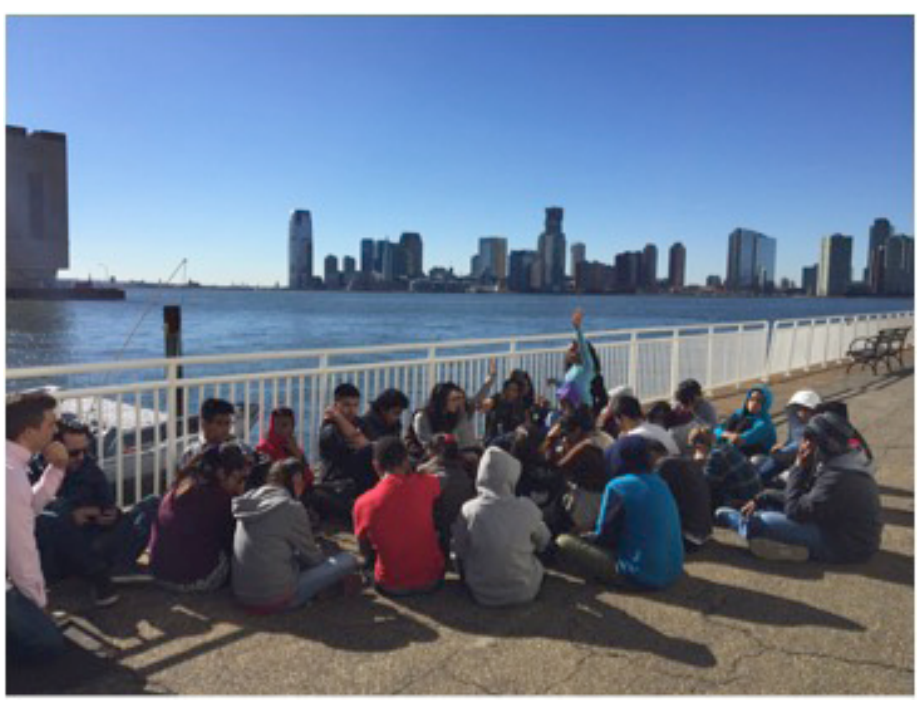

Figure 1. CCERS students offer ideas during their field trip's opening talk at The River Project, May 2016

The place-based education that The River Project provides is particularly necessary in New York City, where many people are highly disconnected from the local environment. Many local schoolchildren learn about the importance of coral reefs and tropical rainforests, but few can define the term "estuary", despite the fact that NYC developed into the major city it is in part because of its location at the intersection of ocean and river. Orienting students to their geography and local ecosystem, and their role in this ecosystem, helps them "become more conscious" and increases student "accountability outward" towards their local environment (Gruenewald, 2003).

In post-trip surveys, students repeatedly express increased interest in their local environment after attending field trips at The River Project, as well as a desire to become stewards of the New York Harbor ecosystem. Understanding the importance of their local ecosystem and how it is a part of "nature" helps forge personal connections to it, which in turn instills a sense of agency, following the adage, "to know is to care is to act." Enabling students to view wildlife in the context of its actual ecosystem shows students the importance of preserving this habitat and gives them a stake in protecting it.
Partnerships in Place-based Education. While The River Project has demonstrated success in utilizing place-based education to connect students to their local estuarine environment and to foster stewardship, one of the greatest shortcomings of its current programming is that it lacks opportunities for long-term student engagement. The majority of classes attend field trips at TRP as a one-time experience. Although most teachers try to incorporate the field trip into their curriculum, many lack the content knowledge, administrative support, curriculum materials, and/or field equipment to take full advantage of the learning opportunities that exist on NYC's waterfront.

An opportunity to increase long-term student and teacher engagement arose in 2014, when TRP partnered with nine local organizations as part of an NSF-funded project to integrate place-based restoration science into Title I middle school curricula. The Curriculum and Community Enterprise for Restoration Science (CCERS) uses oyster restoration as the focal point for a teaching fellowship program with a two-year stipend that trains NYC public school teachers in hands-on STEM education. Teachers in the fellowship attend regular professional development (PD) workshops to support their in-school and in-field teaching and have access to relevant lesson plans. Each teaching fellow receives an Oyster Research Station, a cage of live oysters that also serves as a temporary trap for mobile organisms and settlement surface for sessile organisms (Figure 2). These cages are deployed throughout New York Harbor at sites where they are relatively close to fellows' schools and easily accessible to teachers and students. Students follow protocols to collect data about the oysters' growth and mortality, the mobile and sessile organisms they observe, various water quality parameters, and local site conditions. Classes upload their data to a shared database called the Digital Platform (see Supplementary Materials), so that other students and researchers can access the data in almost real time.

The CCERS program is organized into five programmatic pillars under the administration of principal investigators and senior personnel from the Billion Oyster Project, Pace University School of Education, Columbia University's Lamont-Doherty Earth Observatory, New York Academy of Sciences, and the University of Maryland's Center for Environmental Science. The River Project is one of ten partner organizations that comprise the programmatic pillars of the enterprise: teacher training, student learning, Digital Platform application, after school mentoring, and marine science research (Figure 3). As part of the fifth pillar of CCERS, marine research, TRP provides a vital public space and dedicated staff for teacher trainings and field trips for students. There is no comparable site in NYC at which teachers and students can learn about the estuarine ecosystem first-hand and gain proficiency in urban field science methods.

TRP has provided oyster restoration-themed field trips 


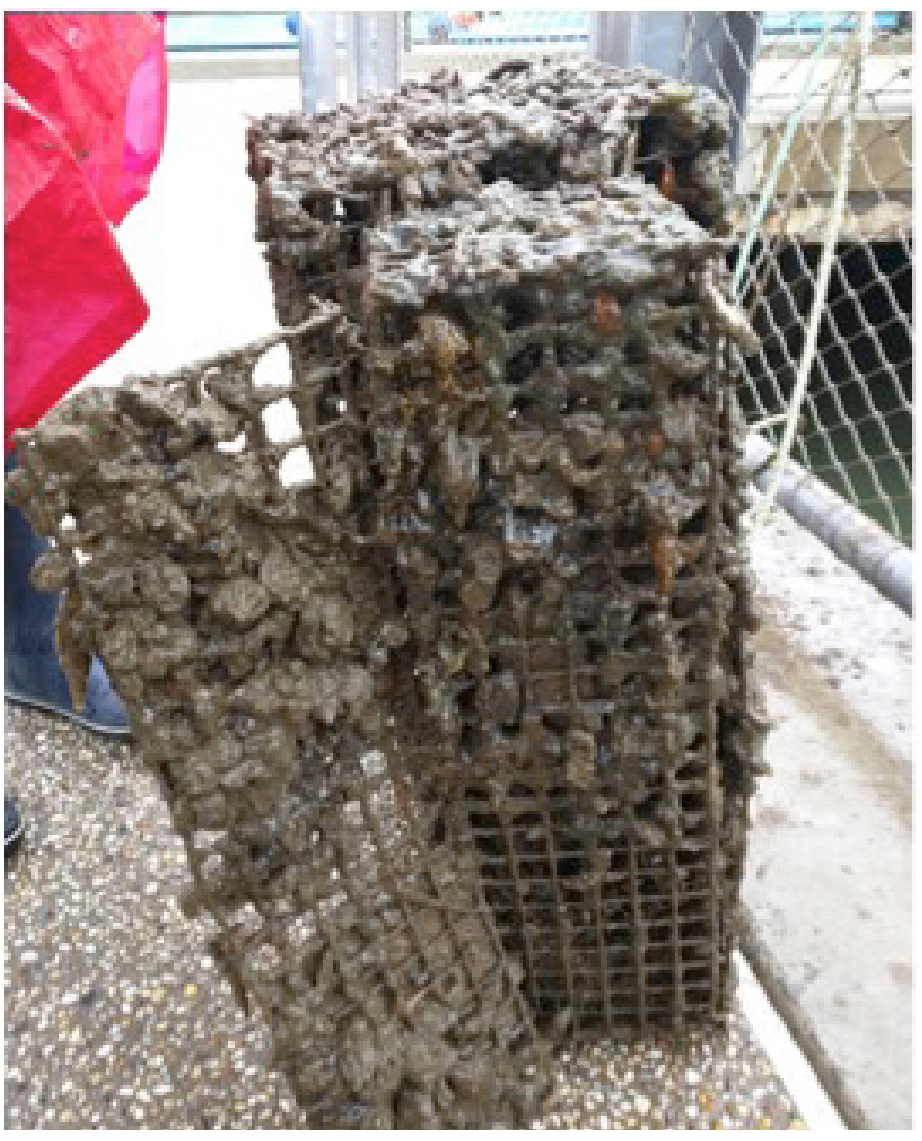

Figure 2. An Oyster Research Station covered in sediment and estuarine organisms. Photo courtesy of Heather Flanagan, 2016 for over 1,600 students of teachers in the fellowship. However, the impact of these field trips has been magnified manyfold by the scaffolding provided by CCERS. Through this partnership, TRP has been able to engage with the same cohorts of students and teachers for over two years through field trips, in-classroom lessons, professional development workshops, and research symposia. This long-term, multipronged program enables TRP's mission to educate the public about the vitality of the Hudson River Estuary to impact students in a meaningful and lasting way. TRP also continues to serves as a resource for teachers after they have completed the fellowship.

\section{EDUCATIONAL STRATEGIES}

Restoration Ecology Supports Place-Based Education. The CCERS program uses oyster restoration as a vehicle for integrating experiential place-based education into K-12 STEM curriculum. This program enhances student connection to their local community by "emphasizing hands-on, real-world learning experiences... [which] increases academic achievement, helps students develop stronger ties to their community, enhances students' appreciation for the natural world, and creates a heightened commitment to serve as active, contributing citizens" (Sobel, 2005). Furthermore, this project specifically aligns with the goals of place-based education by incorporating the natural and built history of

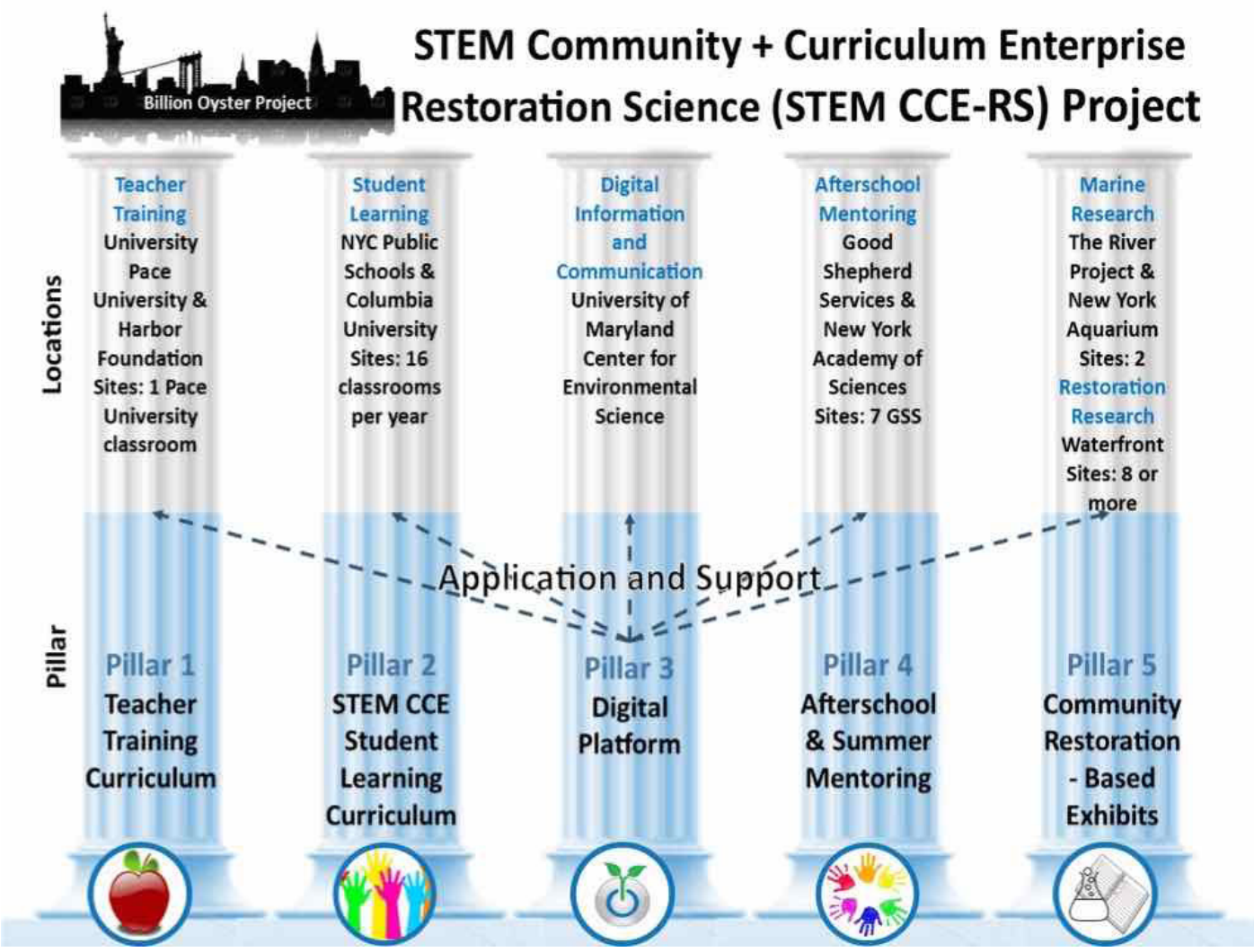

Figure 3. The CCERS fellowship is organized into five programmatic pillars comprised of ten partner organizations. Image courtesy of CCERS. 
New York Harbor into the curriculum, teaching students both about their local environment and also their impact on it (Sobel, 2005). This gives the students ownership over their work, helping them feel like stakeholders in the restoration rather than simply observers.

While restoration of the Eastern oyster and its ecosystem services is a natural fit in New York City, the CCERS model can be utilized by curriculum developers throughout the world with a focus on different species of ecological importance. The Eastern oyster (Crassostrea virginica) was chosen by the founders of CCERS as a species of focus because of the oyster's critical role in the social and ecological history of New York City. Oysters were abundant in New York Harbor when the Dutch colonized the city in the 17th century, and provided a source of food, culture, and revenue for native and colonial New Yorkers for hundreds of years until the native population began to collapse (Franz, 1982).

Oysters also played a major ecological role in New York Harbor as a keystone species on which the larger ecosystem depended. These ecosystem engineers create permanent habitat for hundreds of species in the estuary. Microscopic plankton, countless macroinvertebrates, and fish such as the skilletfish (Gobiesox strumosus) and oyster toadfish (Opsanus tau), collectively known as "reef associates", make oyster reefs their home (Raj, 2008). Oysters are also an important source of food for several estuarine species. However, after hundreds of years of overfishing and pollution, NYC's wild oyster population has become functionally extinct, reducing the populations of many reef associate organisms along with it (Stanne, 2015).

The oyster restoration curriculum developed by the CCERS program provides a place-based lens through which students can better appreciate their city's unique maritime history and more fully understand the ecological structure of their surrounding aquatic ecosystem. Moreover, the curriculum creates opportunities for students to work in the field in their communities, utilizing multiple facets of STEM learning, including making observations, collecting data using scientific instruments, and recording and organizing data on the digital platform. The data students collect about oyster growth and mortality in different sites throughout New York Harbor enables the Billion Oyster Project, a key partner in CCERS, to better understand which locations are ideal for constructing oyster reefs for the purpose of restoration. In taking part in this process, students become facilitators of local restoration and gain greater appreciation for stewardship of their environment.

The River Project contributes to the CCERS place-based education model through its unique flow-through-system aquarium. The aquarium houses native Hudson River animals, including a living oyster reef in unfiltered river water, allowing students of teachers in the CCERS fellowship to observe organisms that are usually obscured beneath the sur-

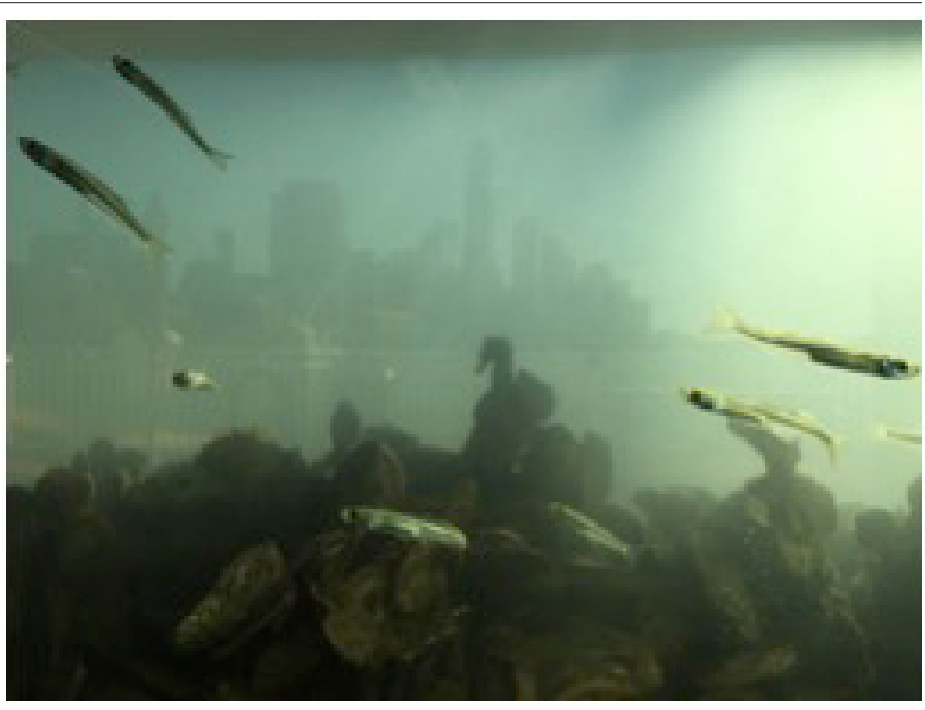

Figure 4. A lined seahorse and Atlantic silversides populate the Living Oyster Reef Ecosystem Exhibit at TRP, 2015

face behaving approximately as they would in the wild. TRP has long used oysters as a teaching tool (Figure 4) in order to demonstrate the vibrant ecological history of NYC and the progress that's been made in cleaning up the Hudson River; TRP's work with CCERS partners, which include ichthyologists and oyster farmers, has strengthened its educators' abilities to teach about oysters by providing a wide range of resources on oyster physiology and ecology.

Collaboration Enables Project-Based Learning. Project-based learning (PBL) enables students to think about the greater environment and their role in it. PBL represents student-centered, inquiry-based, long-term projects that reach beyond the confines of typical schooling to feel more realistic, and are central aspects of curriculum rather than periphery (Lattimer, 2011). Focusing on a real project helps students learn "to think deeply and critically about their world" (Behizadeh, 2014), while also allowing students to construct knowledge on their own terms without simply following their teacher's instructions (Martinich, 2006). They are particularly successful when they connect students to outside, community-based organizations, thereby allowing students to feel like a part of a greater initiative than what occurs only in their classroom (Lattimer, 2011).

This type of partnership is inherent in the CCERS project, connecting teachers, their students, and local science organizations to conduct a field project in New York Harbor. Each fellowship teacher's Oyster Research Station becomes the centerpiece of their classes' year-long projects. Many fellows also have a classroom oyster tank maintained by their students, to be used as an extension of their research when the class cannot get outside to the harbor. Every June, the CCERS program hosts a Billion Oyster Project Research Symposium, in which students present posters of data they collected through their oyster restoration research. In past 
years, students have chosen a range of topics to present on, such as water chemistry, species biodiversity in their oyster station, the effect of pollution on oyster growth, and more.

TRP has collaborated with curriculum specialists from Billion Oyster Project to contribute to the project, while also creating and implementing in-class lessons and professional development workshops supporting CCERS curriculum. This has enhanced the project-based learning goals of CCERS, which focus on incorporating oyster restoration into an entire year-long teaching arc, rather than doing field research without deeper context in the classroom.

Some CCERS teachers work in schools that support project-based learning and student-driven inquiry research, but many do not. One of the professional development goals of CCERS has been to support this kind of teaching while providing a compelling context for it. The CCERS curriculum includes dozens of one-off lessons that teachers can use to enrich their students' field work experience, on topics ranging from reading a map of New York Harbor, to the design of artificial oyster reef structures, to watersheds and sewersheds and NYC's problem with Combined Sewer Outfalls. In addition, the program provides teachers with a series of longer Investigations, or complete units that build up to culminating tasks such as:

- determine the necessary conditions and maintenance schedule for keeping oysters in a classroom tank

- investigate the most likely cause of oyster mortality in a classroom tank, develop strategies for slowing the buildup of toxic ammonia and nitrites, and decide when the tank is ready for more animals, and which kinds

- understand how to read a professional scientific journal article about local amphipod food selection

- define a "steward-shed" - a small part of a local watershed that the class chooses to steward - and investigate the sources of pollution and runoff, engage with local community stakeholders, and propose changes to reduce both runoff and pollution within the steward-shed

The goal of CCERS in producing curriculum is to make it possible for teachers to replace their existing curriculum with restoration science curriculum, rather than just 'tacking on' a lesson here or a field trip there, when they can find the time. The hope is for this curriculum to improve everyday science instruction, rather than being reserved for special occasions or the very rare 'down time' that a teacher can scrape together.

As such, CCERS carefully aligns its investigation units with city and state standards, while keeping the PBL connectivity. The intent is that teaching the restoration science curriculum will address all the topics required of NYC teachers, and prepare students with the relevant skills and content knowledge that they will be tested on at the end of 8th grade. Because standards and testing can be a shifting landscape, CCERS Investigations are also aligned with specific Next
Generation Science Standards (NGSS) performance expectations. Each lesson provided for teachers contains the aligned standards from New York State and NGSS, and can be accessed on the Billion Oyster Project Digital Platform (see Supplemental Materials).

CCERS Curriculum is designed to support academic progression toward the Billion Oyster Project Research Symposium, where students present their original research: primarily field studies using data from the citywide Billion Oyster Project Digital Platform. As the years progress, schools and other citizen scientists continuously upload data to that Digital Platform, making it an ever more valuable local resource for students, teachers, and professional scientists. TRP and Billion Oyster Project educators work closely together, and with teachers and students, to support students' original research, especially through field trips, professional development workshops, and in-class lessons.

\section{THINKING ECOLOGICALLY}

The River Project's 'classroom' is the Hudson River Estuary surrounding and running through it. When CCERS students visit the Wetlab, they are able to interact directly with the estuary and its inhabitants. Field trips comprise three activities: observing and handling common estuarine species in the Wetlab aquarium, while exploring habitat and interspecies relationships; testing water quality parameters (temperature, salinity and turbidity) to draw connections between these abiotic factors and organisms' health; and learning about oyster physiology through dissecting oysters (Figure 5) and observing a living oyster reef ecosystem. Beyond these central activities, the space itself fosters ecological thinking: students observe the green color of the estuary and raise questions about plankton that provide the basis of life for so many animals; they watch the tide during their visit and draw conclusions about the nature of brackish water, and how this affects the species that inhabit estuaries. All students who attend CCERS field trips at The River Project take an exit survey before leaving, answering

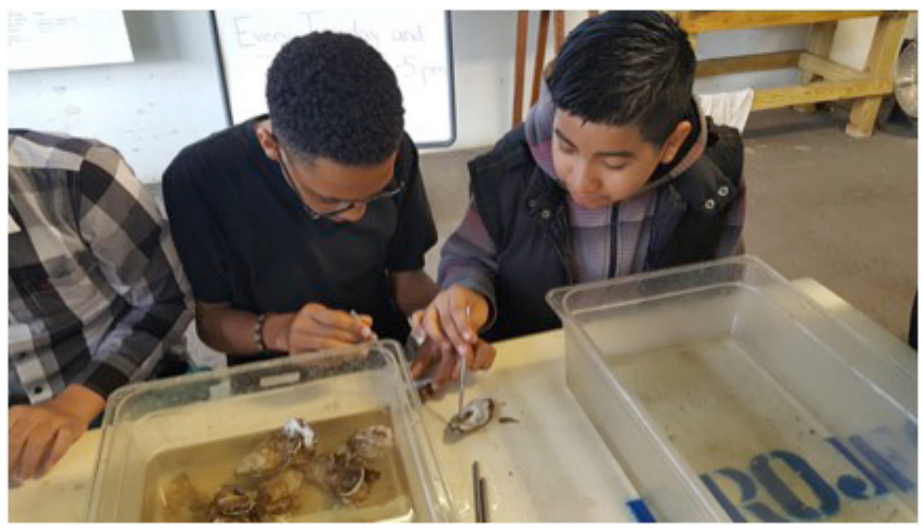

Figure 5. Students explore oyster anatomy and shells using probes in TRP's Wetlab, Spring 2017 


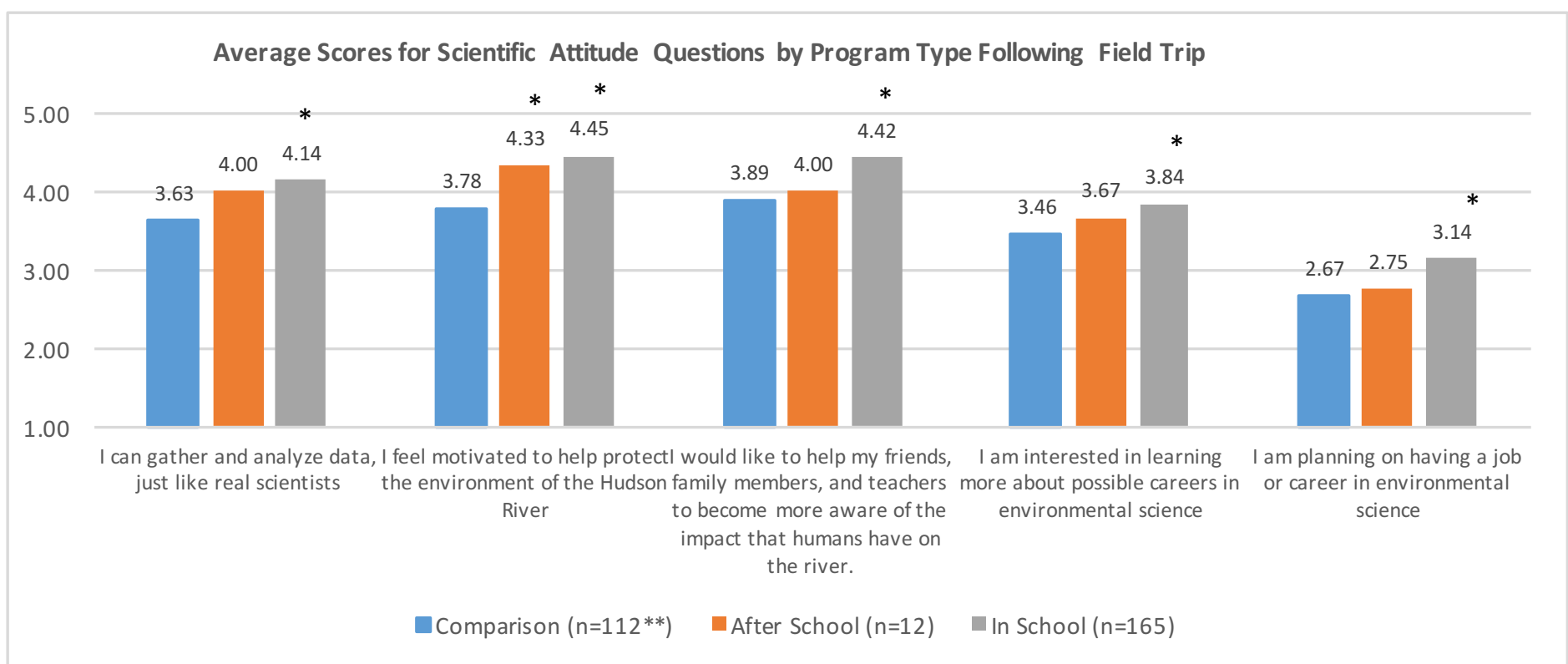

Figure 6. Attitudes toward science for students in the in-school and afterschool CCERS program compared to comparison students, $(* \mathrm{p}<0.05$, paired $\mathrm{t}$-test; $* *$ the difference in the $\mathrm{n}$ of the three groups is a factor that may misrepresent the outcomes). Gaylen Moore Program Evaluation Services, 2016.

questions about their knowledge of the estuary, as well as their behaviors and attitudes surrounding the Hudson River, the environment, and interest in environmental careers. The answers are compiled and analyzed by the project evaluator, and presented at all quarterly meetings for the CCERS as a whole.

All students begin their trips with a geographic and historic orientation of The River Project, the Hudson River Estuary, and New York Harbor. Though all students involved in the project live in New York City, many live and attend school in landlocked areas in the outer boroughs and are unfamiliar with local estuarine ecology. Familiarizing students with local waterways is crucial for the development of the CCERS project as a whole, and also for fostering stewardship and positive attitudes among students toward their local environment through place-based education. In surveys administered to students at the conclusion of field trip sessions, one student reported, "the Hudson River is not polluted, it just has a lot of plants", referring to the greenish color of the water and the phytoplankton that provide the hue. Changing perceptions about the biodiversity and abundance of organisms in the ecosystem is critical to expanding stewardship, and more field trip visitors from the CCERS program than comparison groups report a desire to help protect the Hudson River ecosystem.

Learning about other abiotic (physical, non-living) factors, as well as oyster anatomy and the holistic ecology of the estuary, also drives environmental lessons home for students. These field trips empower students to feel more like scientists while testing water quality parameters, performing dissections on oysters to learn about their physiology and feeding, and handling live animals that they will encounter in their Oyster Restoration Stations. Data collected from the student surveys demonstrate improved understanding of local ecology, particularly the estuarine systems on which oysters rely. Students consistently report comprehension of oysters as ecosystem engineers and keystone species, such as one survey response recognizing that empty oyster shells "provides homes for fish", or that oysters are "food for other species."

\section{PROGRAM EVALUATION}

Data used to understand the effectiveness of the CCERS program was collected and analyzed by an independent evaluator. The evaluator used a quasi-experimental research design to evaluate the effectiveness and impact on the teaching fellows and their students. The evaluator collected both qualitative and quantitative data from participants. With the assistance of the participating sites, the evaluator identified comparison and treatment classes of students to assess the benefits of this model. The comparison student groups were selected from the sites targeted for participation in the program. The comparison groups were not direct participants of in-class CCERS program activities but participated in the same evaluative research activities as the experimental group, including student surveys, and some students also attended field trips at The River Project.

To assess the effectiveness of program implementation and the impact on the target populations, the evaluator used the data collected from research activities, including data from the experimental and comparison student groups at each site. Outcomes were compared using paired t-tests to assess the impact of the program treatment. All student sur- 
veys have an approved IRB protocol with the New York City Department of Education, and the teaching fellow surveys have an approved IRB protocol with Pace University.

Likert-scale surveys administered to students who participated in field trips at TRP as part of the in-school or after school components of the CCERS program captured information on student attitudes toward science (Figure 6). Students rated their attitudes towards statements such as, "I can gather and analyze data, just like real scientists" and "I am interested in learning more about possible careers in environmental science." Survey responses indicated that students who participated in the in-school program showed an increase in scientific attitude scores compared to students in the control group who did not participate. For all survey questions, responses for in-school participants were significantly higher than comparison students who did not participate. Responses from students in the after school program trended higher than comparison students, but students only demonstrated a statistically significant increase in attitude score in response to the statement, "I feel motivated to help protect the environment of the Hudson River." Overall, results of the evaluation suggest that students who participate in the CCERS program develop positive attitudes towards science, environmental stewardship, and related careers.

\section{PARTNERSHIPS ENABLE LONG-TERM ENGAGEMENT}

Deepening Teacher Involvement: Professional Development Workshops. For most CCERS teaching fellows, field science is an unfamiliar arena. TRP is unparalleled in NYC in its ability to provide direct access to the Hudson River and expertise in urban ecology fieldwork. Therefore, TRP is in a unique position to provide, in collaboration with CCERS

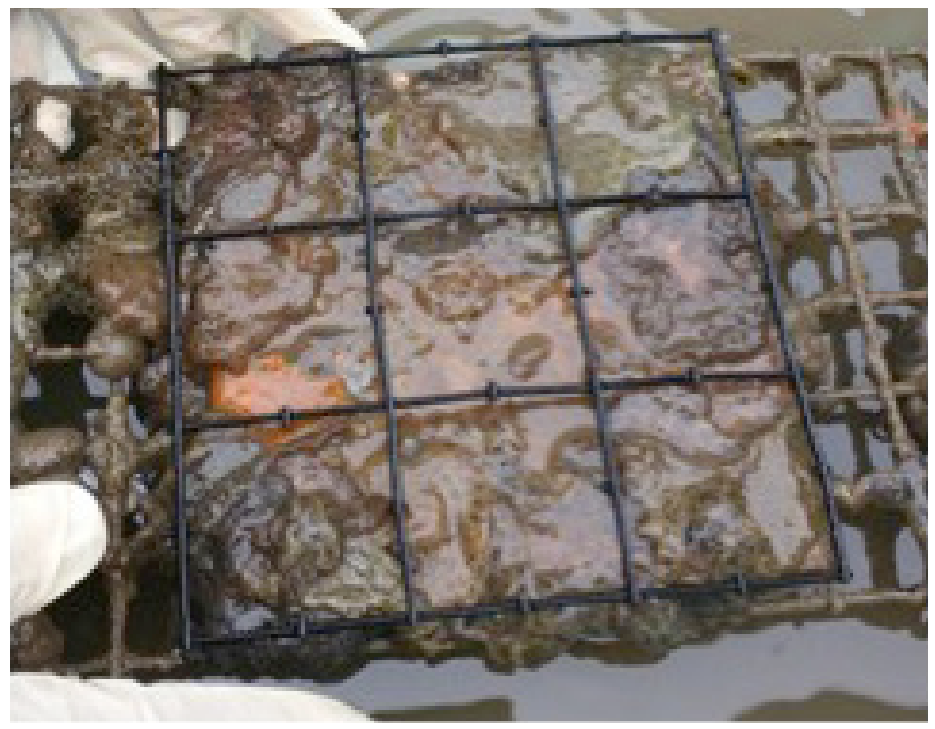

Figure 7. A settlement tile on an ORS covered in sessile organisms. Photo courtesy of Heather Flanagan, 2016 curriculum specialists, professional development workshops on topics related to restoration field science. The PD workshops have covered two topics: introducing organisms commonly found in the Oyster Research Stations (Creatures at The River Project), and using microscopy to identify and understand estuarine plankton (Plankton Ecology). Based on widely positive anecdotal and survey responses from teachers who attended these workshops, and numerous requests from those who were unable to attend, TRP hosted and plans to host these PDs biannually.

The Creatures PD was created because many teachers expressed frustration at their inability to identify organisms they and their students found on their Oyster Research Station. Identification is one facet of the Oyster Research Station data collection protocol, but to the inexperienced eye, a settlement tile covered in sessile organisms might appear to be a blob of inanimate slime (Figure 7). TRP's PD workshop sought to teach identification skills with the larger goal of fostering more attentive observation, and developing a vocabulary to support thoughtful, scientific discussions about complex ecological communities.

The PD began with a scavenger hunt, during which teachers searched for examples of common oyster reef associate organisms throughout the Wetlab, working together to identify different species. Next, the participants devised various ways their students might categorize the live organisms in front of them (Figure 8). To elaborate on one accepted method of classification, TRP educators reviewed the taxonomic categorization of these organisms. Participants were then introduced to a method of identification utilizing categorization, the dichotomous key. This activity utilized an in-house dichotomous key to identify common TRP fish, and provided an opportunity for teachers to learn fish anatomy. The participants brainstormed how to guide students through creating their own keys for Oyster Research Station animals to encourage them to think about differences between these organisms and how to best categorize them.

The goal of the Plankton PD was to introduce teachers to the organisms that comprise the foundation of the estuarine food web, and to provide viable fieldwork for winter months. Diatoms, silicate-encased phytoplankton (plant-like organisms that float with the current), are among the most fascinating and beautiful Hudson River plankton. These intricately-shaped autotrophs reproduce rapidly and bloom in late winter due to nutrient upwelling in the estuary, presenting an ideal opportunity for examining these organisms and the heterotrophic zooplankton (animal-like plankton) that feed on them (Stanne, 2007). They are also the main food source of oysters, making them important components to study for this project (Raj, 2008).

Plankton are particularly difficult to study because visualizing them often requires a microscope and because classifying them is so complex that their taxonomy remains a 

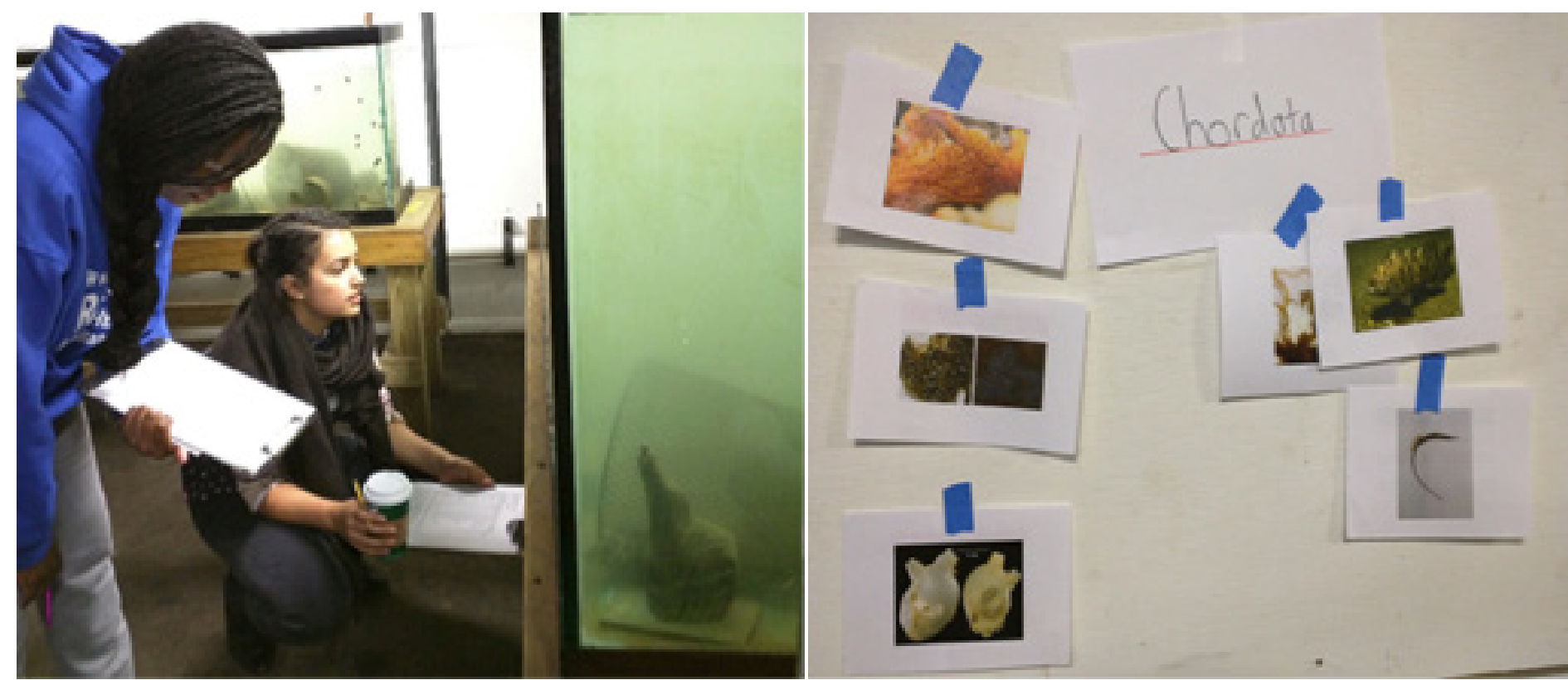

Figure 8. Teachers explore the Wetlab for organisms on their scavenger hunt, and investigate species' phyla and relationships at the Creatures PD, November 2016. Photos courtesy of Heather Flanagan

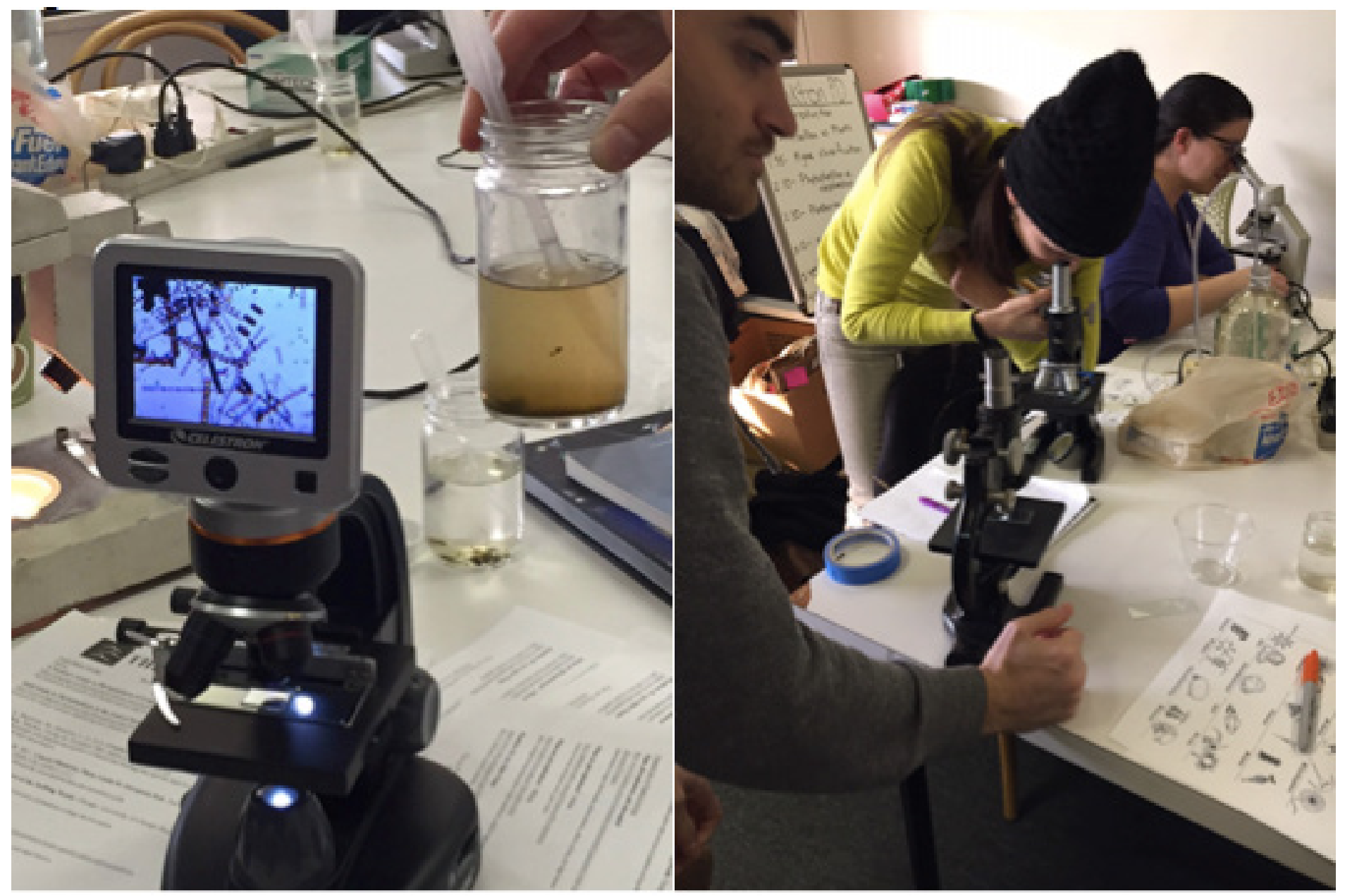

Figure 9. Teachers look for phytoplankton under microscopes from a Hudson River plankton sample, 2017 
debate among experts. At the beginning of the PD, the teaching fellows were presented with images of various types of plankton and given the opportunity to categorize them in order to elucidate differences and similarities at multiple levels of classification. Teachers then went into the field to collect plankton samples using both a science-grade plankton net and a "homemade" net that could be constructed by students. Teachers viewed these samples under a microscope and practiced identifying species using field guides (Figure 9).

PD workshops have proven valuable for the enhancement of teachers in their fellowship program and in their classrooms. In surveys administered by CCERS curriculum specialists after the Creatures PD, several teachers expressed having a clearer understanding of the organisms and their relationships. One teacher utilized content taught during the PD by having her students make their own dichotomous keys and reached out to TRP educators and curriculum specialists to solicit further advice for carrying out the lesson. Another teacher took lessons from the Plankton PD back to the classroom, reporting that her "kids didn't want to leave school. They wanted to keep looking in the microscope."

These PD sessions were designed to support the year-long project-based learning progression toward the Billion Oyster Project Symposium. At the 2016 Symposium, nearly all the research projects used oyster growth data and/or water quality data. The 2017 Symposium featured a wider array of research questions, specifically on topics that were covered in TRP PD workshops, including posters that quantified organism biodiversity, studied animals other than oysters, and/ or considered planktonic communities in the estuary. This suggests that workshops provided by TRP enabled teaching fellows to provide support for their students' research on a wider variety of topics related to oyster restoration. In 2017, five teachers in the CCERS fellowship brought more than two distinct student research posters to the Symposium. Nearly all of those teachers attended TRP PD workshops and developed ongoing relationships with TRP educators, potentially indicating that curriculum support from TRP enabled fellows to enrich the breadth and depth of study they could facilitate among their students.

Bringing the Estuary to the Classroom: In-class Programming. TRP has worked to provide in-class programming for quite some time, but lacked the organizational relationships and funding to establish a robust program. CCERS was able to provide both, giving TRP educators the opportunity to contribute to restoration curriculum, especially in the winter months. CCERS field work slows down at this time because of frigid temperatures, as oysters are dormant and many associated organisms hibernate or migrate to warmer waters. Because TRP's Wetlab is closed during this time because its animals are released seasonally to continue their natural life cycles, TRP staff designed hands-on activities that could easily be done in the classroom.
Oyster anatomy and plankton exploration stood out as both relevant to CCERS and feasible for an in-class lesson. While many students know buzzwords about oyster feeding, few fully understand how the bivalve's anatomy is suited to feeding on plankton in the water and what these plankton actually look like. Sixth and seventh graders showed excitement, curiosity, and scientific engagement while dissecting oysters and comparing their anatomy to that of a human. Several students expressed amazement that "this is something people eat!" and some even ventured to taste their first oyster on the half shell. The plankton lessons elicited similar exclamations of delight and fascination. TRP educators collected plankton samples prior to their classroom visit and brought them to classrooms to explore the importance, proliferation, and biodiversity of producers in the Hudson River Estuary. Many students reported being surprised that they "saw anything in the microscope" when looking at Hudson River samples, and nearly every student was shocked to learn that the character Plankton from Spongebob Squarepants represented a real organism found in their local estuarine ecosystem, the copepod (Figure 10).

These in-class lessons provided a valuable experience for teachers, students, and TRP educators alike - a way to incorporate field science into daily curriculum; an opportunity for students and teachers to connect with local scientists and their research; and an opportunity for TRP to forge a deeper connection with students than is normally possible in a 90-minute field trip. It also provided a forum for teachers to form closer relationships with educators at TRP, who provided assistance in future lesson planning and field studies. Several teachers contacted TRP educators months later with photographs to try to identify organisms in their Oyster Research Station. One teacher even enlisted TRP educators to be interviewed by two students for their Symposium project. This kind of communication is one of the goals of project-based learning, and strengthened the CCERS program immensely.

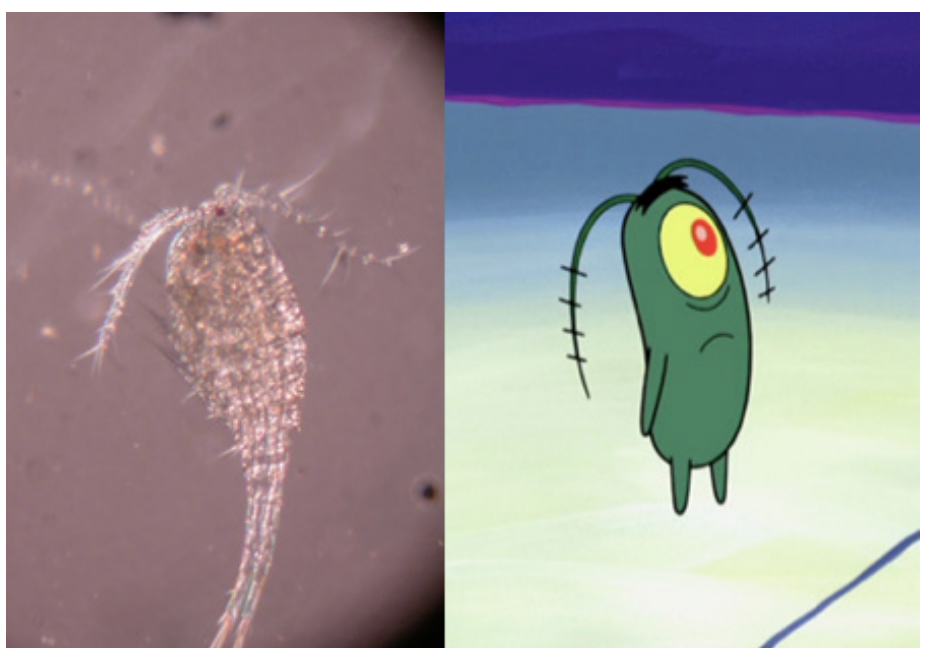

Figure 10. Slide comparing photo of Hudson River copepod to Spongebob Squarepants' Plankton 
Opportunities to Extend the River Project's Reach. The River Project has been providing place-based environmental education since 1995, filling a void in local estuarine ecosystem education. Teachers return year after year, but students rarely obtain more than a 90-minute introduction to estuarine life before returning to their classrooms for largely unrelated curriculum.

The CCERS program bridged this gap by providing a place-based framework for project-based learning on oyster restoration, using TRP as a platform for conducting explorations into estuarine biology, ecology, and chemistry. Students and teachers have been given the resources to explore topics of their interest whether through a field trip, professional development workshop, or in-class lesson.

Teachers who participated in one or more of these experiences have shown more engagement with the fellowship, and their classes have demonstrated higher levels of comprehension in their classrooms and at the Symposium. The synergy of programming proved to be more valuable than any one experience a student or teacher could have received, demonstrating the viability of place-based education and project-based learning for teaching STEM in New York City.

\section{ASSOCIATED CONTENT}

Billion Oyster Project blog post on Creatures PD:

https://www.billionoysterproject.org/whats-under-newyork-harbor/

Billion Oyster Project blog post on Plankton PD: https:// www.billionoysterproject.org/7-reasons-to-get-excitedabout-plankton/

Billion Oyster Project Curriculum and Community Enterprise for Restoration Science Tumblr: http://bop-ccers.tumblr.com

Billion Oyster Project, Schools and Citizen Science photo collection:

https://www.flickr.com/photos/nyhf/collections/72157682412678916/

NYC Media video, That's So New York: The River Project: http://a002-vod.nyc.gov/html/recent.php?id=3392

The River Project:

www.riverprojectnyc.org

Billion Oyster Project Digital Platform (requires login): https://platform.bop.nyc/

Excerpt of a lesson sequence from Fellow Aniline Amo- guis of Young Women's Leadership School of Astoria that began February 2017, with edits from CCERS curriculum specialist

Survey administered to all students of CCERS teaching fellows after field trips at The River Project. Gaylen Moore Evaluation Services, 2016

\section{AUTHOR INFORMATION \\ Corresponding Author}

Elisa Caref. Sarah Lawrence College, Center for the Urban River at Beczak, Yonkers, NY;

ecaref@sarahlawrence.edu

\section{Author Contributions}

The manuscript was written through contributions of all authors. All authors have given approval to the final version of the manuscript.

\section{FUNDING SOURCES}

The work described in this article is supported by NSF grant \#1440869, Curriculum and Community Enterprise for New York Harbor Restoration in New York City Public Schools.

\section{ABBREVIATIONS}

TRP: The River Project; CCERS: Curriculum and Community Enterprise for Restoration Science; PD: Professional Development; NYC: New York City; STEM: Science, Technology, Engineering, Math; PBL: Project Based Learning; NGSS: Next Generation Science Standards

\section{REFERENCES}

Behizadeh, N. (2014). Enacting problem-posing education through project-based learning. The English Journal, 104(2), 99104.

Franz, D.R. (1982).An historical perspective on mollusks in lower New York harbor, with emphasis on oysters. Ecological Stress and the New York Bight: Science and Management, 181-97.

Gruenewald, D.A. (2003). A multidisciplinary framework for place-conscious education. American Educational Research Journal, 40(3), 619-654.

Lattimer, H.,and Riordan, R. (2011). Project-based learning engages students in meaningful work: Students at High Tech Middle engage in project-based learning. Middle School Journal, 43(2), 18-23.

Martinich, J. A., Solarz, S. L., and Lyons, J. R (2006). Preparing students for conservation careers through project-based learning. Conservation Biology, 20(6), 1579-1583. 
Raj, S., and Reson, P.J. (2008). Oysters in a new classification of Keystone species. Resonance, 13, 648-654

Sobel, D. (2005). Place-Based Education;Connecting Classrooms and Communities. Great Barrington, MA: The Orion Society.

Stanne, S.P., Panetta, R.G., and Forist, B.E.(2007). The Hudson: An Illustrated Guide to the Living River. New Brunswick, New Jersey: Rivergate Books.

Stanne, S.P. (2015).The State of the Hudson 2015. Hudson River Estuary Program:New York State Department of Environmental Conservation. 